\title{
Financial Security Evaluation in Power Production Industry Based on BP Neural Network Optimized by Genetic Algorithm
}

\author{
Lin $\mathrm{Jiao}^{1}$, Shuo $\mathrm{Yao}^{2}$, Di Jiao ${ }^{3}$ \\ ${ }^{1}$ School of Continuing Education, Hebei Finance University,Baoding, 071000, China \\ ${ }^{2}$ Financial section of Heibei Science and Engineering School,Baoding, 071000, China \\ ${ }^{3}$ International Business Department,Agricultural Bank of China Shijiazhuang Dongcheng \\ Sub-branch, Shijiazhuang, 050000, China
}

Keywords: financial security;power production industry; genetic algorithm; BP neural network; evaluation

\begin{abstract}
In recent years, power production industry investment and financing security issues have become increasingly prominent in China, which has brought serious financial security challenges to our country's power production industry. Therefore, to evaluate the financial security is of vital significance.This paper selects genetic algorithms (GA) to optimize the traditional BP neural network algorithm,and establish BP neural network model improved by genetic algorithm. Using GA algorithm to optimize the connection weights and thresholds of BP neural network,giving full play to the global optimization capability of GA algorithm and local search advantage of BP algorithm.So,it can be a good way to overcome the problem of BP neural network--weights of which are random.Through the practical experiments,the results indicate that prediction results based on BP neural network optimized by genetic algorithm,can evaluate the financial security of Chinese power production industry effectively.Moreover,the operation process of the model not only has a fast convergence rate,but also the prediction results has high accuracy.
\end{abstract}

\section{Introduction}

With the outbreak of the 2008 world financial crisis and the spread and complexity of the international political situation increases, investment security issues in financial development of our country's power production industry have become increasingly prominent, which has brought serious financial security challenges.Therefore, in today's situation,we need to formulate the index system for evaluating power production industry's financial security,and build a set of perfect financial security evaluation model in order to escort China's power production industry.Now, all of these are problems and strategic opportunities our country are facing.

Production safety is a central part of power enterprises,but the economic security problems should not be overlooked.That is to say,under the macroeconomic background at home and abroad,power enterprises how to ensure their financing needs and investment security issues [1].

Energy Finance is a new research topic,related to which has not yet commenced a systematic in-depth study both at home and abroad.Chuanzhe Liu etc[2] studied the connotation of energy finance,and pointed out problems that energy finance need to study. Fujun Wen and Conglai Fan analyzed the construction of energy industry's financial support system from the perspective of strategy and put forward--to build the energy industry policy support system need to study and formulate investment and financing framework of energy development;meanwhile build energy industry financial risk prevention system [3].Fujun Wen and Zhao believe there are still many financial problems in our country's energy development.For example,there exists contradictions between coordination of industrial policy and credit policy; industry concentration loaning from financial institutions is too high;energy enterprises' financing approach is single;and energy financial support and energy industry development pro-cyclical [4].Kaifeng Li and Chuanzhe Liu proposed the definition of coal industry's financial security from a view of financial science and security science.As well,they think financial security management in the process of coal enterprises financing and investment is an important guarantee to our country's energy security.We can analyze 
the factors that affect the financial security of the coal industry from three aspects including macroeconomic conditions, financing conditions and investment conditions.

Therefore,this paper presents a method that is BP neural network optimized by genetic algorithm to evaluate the financial security of our country's power industry.BP neural network is a kind of multilayer feedforward network according to the error back-propagation training algorithm,which is one of the most widely used neural network model currently.But,while training,it is easy to fall into local minimum values and convergence speed is slow at the same time.In this paper,utilize the good global search ability of genetic algorithm to train the connection weights and thresholds of BP neural network an establish the GA-BP model.The new model can make up for shortcomings in the learning process of BP neural network,such as slow convergence speed,easiness to fall into local minimum point and poor robustness effectively.Through the empirical analysis,verify the validity and practicability of BP neural network optimized by GA in financial safety evaluation of power industry.It can provide reference for financial security evaluation of the energy industry in future[2].

\section{Evaluation index system of power financial security}

In this paper,construct comprehensive evaluation index system of power financial safety from three aspects of the macroeconomic environment security,energy finance financing security implications and energy financial investment security implications.In terms of macro-economic security,select six indicators, that is GDP growth,CPI based data,business climate index, exchange rate volatility, loan growth and financial revenue and expenditure ratio.In terms of energy finance financing security implications,choose asset-liability ratio,current ratio,debt-to-equity ratio and interest coverage ratio these four evaluation index.In the aspect of energy financial investment security,two evaluation indexes including rate of return on assets and profit rate of the primary business are selected[3] .The index system as shown in table 1.

Table 1 Comprehensive evaluation index system of financial security in power production industry

\begin{tabular}{|c|c|c|}
\hline Level indicators & Secondary indicators & Tertiary indicators \\
\hline \multirow{12}{*}{$\begin{array}{c}\text { Comprehensive } \\
\text { evaluation index system } \\
\text { of financial security in } \\
\text { power production } \\
\text { industry }\end{array}$} & & GDP growth $\left(A_{1}\right)$ \\
\hline & & CPI based data $\left(\mathrm{A}_{2}\right)$ \\
\hline & Assessment indicators of & business climate index $\left(A_{3}\right)$ \\
\hline & macroeconomic environment & exchange rate volatility $\left(\mathrm{A}_{4}\right)$ \\
\hline & & loan growth $\left(\mathrm{A}_{5}\right)$ \\
\hline & & $\begin{array}{c}\text { financial revenue and expenditure } \\
\text { ratio }\left(A_{6}\right)\end{array}$ \\
\hline & Assessment indicators of & asset-liability ratio $\left(\mathrm{B}_{1}\right)$ \\
\hline & financial financing security & current ratio $\left(B_{2}\right)$ \\
\hline & implications of the power & debt-to-equity ratio $\left(\mathrm{B}_{3}\right)$ \\
\hline & industry(B) & interest coverage ratio $\left(B_{4}\right)$ \\
\hline & Assessment indicators of the & rate of return on assets $\left(C_{1}\right)$ \\
\hline & $\begin{array}{l}\text { financial investment security } \\
\text { implications of the power } \\
\text { industry(C) }\end{array}$ & $\begin{array}{l}\text { profit rate of the primary business } \\
\qquad\left(\mathrm{C}_{2}\right)\end{array}$ \\
\hline
\end{tabular}

\section{Genetic algorithm (GA) optimize BP neural network}

The operation object of GA is a population, and each population is composed of several chromosomes. Each chromosome corresponds to a solution. Start from an initial population, use replication, crossover and mutation to produce the next generation of population. Finally the optimal solution is got to meet certain convergence conditions . BP network mode of transmission is divided into two kinds which are forward propagation and back propagation. In the forward 
propagation, the input information transmits from the input layer to the output layer after the hidden layer processing. The state of the neuron in each layer only affects the state of the next layer neurons. In the output layer, after making a contrast between the actual output and expected output, the operation turns to the back-propagation and the error signal returns along the original neurons if the actual output does not meet the requirements. In the return process, the weights linking each layer are modified one by one. This process is continuous. Finally the error is within the scope allowed. Its mathematical description as follows[4]:

$$
\left\{\begin{array}{l}
\min E_{1}(\boldsymbol{w}, \boldsymbol{v}, \theta, r)=\frac{1}{2} \sum_{k=1}^{M} \sum_{t=1}^{n}\left[y_{k}(t)-\hat{y}_{k}(t)\right]^{2} \\
s, t: \boldsymbol{w} \in R^{m \times p}, \boldsymbol{v} \in R^{n \times p}, \theta \in R^{p}, r \in R^{n}
\end{array}\right.
$$

$E_{1}$ is the total network error, $y_{k}(t)$ is the desired output, and $\hat{y_{k}}(t)$ is the actual network output.

$$
\begin{aligned}
& \hat{y}_{k}(t)=f\left\{\sum_{j=1}^{p} v_{j t} \cdot f\left[\sum_{i=1}^{m} w_{i j} \cdot x_{i}(t)+\theta_{j}\right]\right\}+r_{t} \\
& E_{2}=\frac{1}{N-N_{1}} \sum_{k=N_{1}}^{N} \sum_{t=1}^{n}\left[y_{k}(t)-\hat{y}_{k}(t)\right]^{2}
\end{aligned}
$$

$E_{2}$ is the mean square error of the test sample, which means the estimate of the output data reliability. The smaller $E_{2}$ is, the more reliable network output is.

In the BP neural network, the weights initialization strongly affect the final solution. The initial weights of different settings may cause great differences on the training time and convergence. In order to better solve the problems of determine the initial weights and threshold, can adopt the weights and threshold based on genetic algorithm, using the global search ability of genetic algorithm to determine the initial weights and threshold.This paper adopts three layer BP network to determine the initial solution space, setting training number and training error of the network. when the training sample error and testing samples are more satisfied, respectively recorded maximum value and minimum value of the connection weights as $w_{\max }$ and $w_{\min }$. Set the solution space of the connection weights as $\left[w_{\min }-\delta_{1}, w_{\max }+\delta_{2}\right] \quad\left(\delta_{1}, \delta_{2}\right.$ is adjusting parameters). The chromosome representation the weights, then the fitness function is the calculation error of the neural network, and the error is larger, the fitness is smaller. The GA fitness function can be use of.

$$
\text { fitness }=\frac{1}{\frac{1}{N} \sum\left[y_{k}(t)-\hat{y}_{k}(t)\right]^{2}}
$$

$y_{k}(t)$ and $\hat{y}_{k}(t)$ are the expected value and the actual value of the network output. $\mathrm{N}$ is constant.Set the input population size, crossover probability $\left(P_{c}\right)$, mutation probability $\left(P_{m}\right)$, the network layers, each layer neural metadata, and use GA to optimize the weights of neural network repeatedly, until the average value is no longer meaningful increase so far, at this time the decoded parameter combination has sufficiently close to the optimum combination of parameters, and then $\mathrm{BP}$ algorithm reoptimization connection weights and threshold of the network in the small solution space, search out the optimal solution[4].

\section{Empirical analysis}

(1) sample selection

This article selects China's quarterly data from 2003 to 2010 and gets 32 samples of original data.Then choose 24 sets of data samples from 2003 to 2008 as the training sample,four groups of data samples from 2009 as the test sample and the data from 2010 as a desired output.Respectively, The samples data are shown in table 2 . 
Table .2 samples date

\begin{tabular}{|c|c|c|c|c|c|}
\hline & $\mathrm{A}_{1}$ & $A_{2}$ & $\ldots$ & $\mathrm{C}_{1}$ & $\mathrm{C}_{2}$ \\
\hline 1 & 0.1080 & 2.0379 & \multirow{10}{*}{$\cdots$} & 0.0043 & 0.0785 \\
\hline 2 & 0.0970 & 2.0134 & & 0.0107 & 0.0750 \\
\hline 3 & 0.1010 & 2.0006 & & 0.0202 & 0.0699 \\
\hline 4 & 0.1000 & 2.0567 & & 0.0258 & 0.7812 \\
\hline 5 & 0.1040 & 2.0942 & & 0.0053 & 0.0634 \\
\hline \multicolumn{3}{|c|}{$\ldots$} & & \multicolumn{2}{|c|}{$\ldots$} \\
\hline 29 & 0.1130 & 2.4187 & & 0.0016 & 0.0168 \\
\hline 30 & 0.1100 & 2.4200 & & 0.0029 & 0.0185 \\
\hline 31 & 0.1060 & 2.4136 & & 0.0035 & 0.0152 \\
\hline 32 & 0.0960 & 2.3992 & & 0.0044 & 0.0170 \\
\hline
\end{tabular}

(2)Model training and results analysis

Using the mathematical model of third section construction carries on processing to the sample data, to obtain the actual output results as shown in table 3. In Table 3,test input is test sample,and expected output is the actual value of each index in 2010.Calculating the error between actual output and the expected output of the absolute value. As shown in Table 3.

Table 3 the absolute error of expected output and actual output

\begin{tabular}{|c|c|c|c|c|c|}
\hline & $A_{1}$ & $A_{2}$ & $\ldots$ & $\mathrm{C}_{1}$ & $\mathrm{C}_{2}$ \\
\hline 1 & 0.0211 & 0.0092 & & 0.0024 & 0.0468 \\
\hline 2 & 0.0127 & 0.0117 & & 0.0039 & 0.0432 \\
\hline 3 & 0.0044 & 0.013 & $\cdots$ & 0.0004 & 0.0355 \\
\hline 4 & 0.0232 & 0.0513 & & 0.0016 & 0.0292 \\
\hline
\end{tabular}

Table 3 is calculated according to absolute error between expected output and the actual output Analysis of table 3 found except the error of interest coverage which is larger than 1,the maximum of other indexes' is 0.1305 and he minimum is 0.0004 . This indicates the vast majority of index prediction accuracy is high and has a good fit.So,the prediction model used in this article can be used to evaluate the financial security of China's power production industry.

\section{Conclusion}

This paper's simulation experimental results shows that weights and threshold of BP neural network optimized by genetic algorithm,the prediction model's possibility of trapped into local minimum is greatly reduced and convergence speed and prediction accuracy improved.And according to the forecasting result and the security interval table of financial security evaluation index in China's power production industry, the evaluation result calculated is in line with the actual situation.This illustrates the constructed index system and the proposed GA - BP model can be used in financial security evaluation of China's power industry.Besides, it can provide reference to other industry's financial safety evaluation. 


\section{References}

[1] FU Jun-wen,FAN Cong-lai.Strategic Thinking on Constructing the Financial Supporting System of Resource Industry[J].Soft Science,2007,21(02):92-101

[2] LI Kai-feng,.Study on the Early Warning Management of China's Energy Financial Security Operation[M],Bei Jing: Science Press,2012

[3] LI Kai-feng,Wang Min-min.Evaluation of China's new energy finance security situation[J]. Friends of Accounting, 2014(1):17-21

[4] LI Ji-zun.Establishment of Chinese energy early warning model and indicators[J].JOURNAL OF CHINA UNIVERSITY OF PETROLEUM(EDITION OF NATURAL SCIENCE), 2007,31( 6) : 161-166.

[5] CHAI Yi,YIN Hong-peng,LI Da-jie. BP neural network adaptive optimization design based on the improved genetic algorithm[J]. Chongqing university journal, 2007,30(4):91-96.

[6] LI Yong,WANG Jian-jun,CAO Li-hua. Real time optimal load dispatch of power plant based on back propagation neural network[J]. Power System Protection and Control, 2011, 39(17):87-92.

[7] GAO Xian-jun,ZHANG Jie,HONG Yu. Neural network technology research Based on genetic algorithm[J]. Equipment manufacturing technology, 2010,2(2):8-10.

[8] ZHU Wen-long.Application research of BP neural network in Multi-objective optimization based on genetic algorithm[D]. Harbin: Harbin university of technology,2009. 